\section{GUIDING YOU THROUGH THE DESIGN MINEFIELD}

Designing a new surgery from scratch and choosing the right equipment can be an exciting challenge - but how do you ensure the end result lives up to expectations and meets your needs both now and for the foreseeable future? Your project can quickly turn to a minefield of dilemmas and decisions.

Help is at hand in Takara Belmont's Manchester and London showrooms where all Belmont equipment is on display and available for demonstration. Their team of consultants will partner with you, and your dealer, to select equipment and design a surgery which meets your unique requirements.
With appointments available in the evening and at weekends, Takara Belmont recognise the importance of being totally flexible around your busy schedule and offer their services free of charge.

The team can also advise you on purchase agreements and payment plans. Warranties and maintenance periods for your equipment will also be a consideration. Takara Belmont themselves offer a five year free extended warranty on chairs and lights, three on units and spittoons and two on X-rays, offering further peace of mind. Reader response number 53

\section{SANITISE IN SECONDS}

Quill International is launching

Supernova Surface Wipes in a bulk size to help hospitals achieve higher levels of sanitisation at a lower price.

The high performance Supernova sanitising wipes have been independently proven effective against 99.9\% of bacteria, spores, viruses and fungi including Clostridium difficile, MRSA and Norovirus.

The larger tubs hold over 1,000 wipes, providing over 1,000 applications of long lasting germ protection to surfaces. The ready to use no water formulation provides easy instant germ protection to surfaces, apparatus and equipment.

The wipes come in a large tub, which is $4.9 \mathrm{~kg}$. This large tub means that Supernova is able to reduce the real costs per wipe and improve product loss prevention.
Each sanitising wipe contains a gentle alcohol free solution which leaves surfaces biologically cleansed and sanitised in seconds.

\section{Reader response number 54}

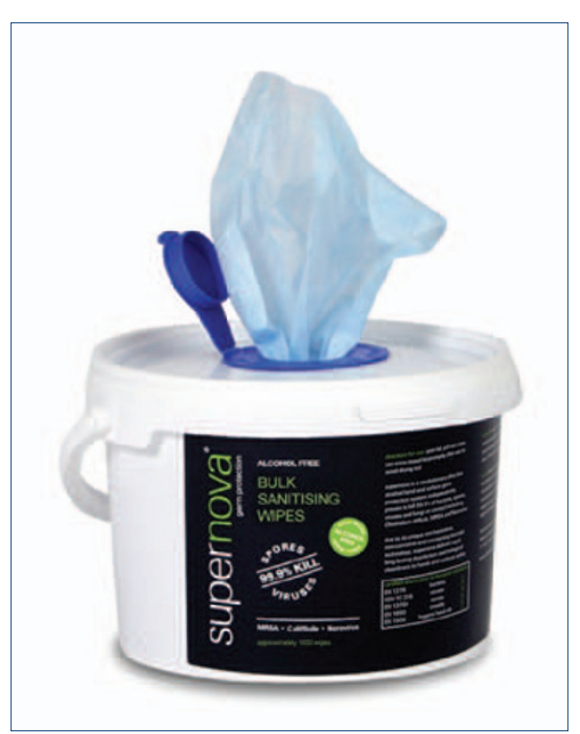

\section{IT FOR DIE HARD PAPER PUSHERS}

The days of mass paperwork stored in rows of filing cabinets are long gone in dentistry. In a modern practice everything is available at the touch of a button; however, some practices are still reluctant to use IT and as a result, are left worse off in terms of efficiency and control. This is the challenge facing IT companies who supply the dental industry and it is exactly this that iSmile has been successful in overcoming.

iSmile has been specifically designed, developed and built for the UK dental market by UK dental practitioners. With this foundation iSmile have managed to develop a simple, easy to use interface which works very similar to standard web browsers. iSmile also provide a single point of contact service where they will manage all IT issues to resolution maintaining contact with all related IT suppliers. This service together with their ability to remotely login to computers to solve problems allows their staff to provide a more personalised service to their customers and enables quick and effective resolution of problems.

iSmile are developing an exciting range of modern devices that will enable practices to fully explore current technology trends. Products including the self service check-in screen, the online booking system and the dental lab asset recording system will be fully integrated with the iSmile Practice Management Systems application and provide a single suite of applications designed and developed specifically for the UK dental market. Reader response number 55

\section{ERADICATING OIL AND MOISTURE}

DentalAir.com manufactures only the most modern dental air compressors. Their products can equip any size of practice, from the smallest of single chair practices to large hospital wards, and are oil-free and virtually silent.

Air compressors that are old or have fallen into disrepair may produce an air supply of inferior quality, which corrodes air-driven instruments such as handpieces and can transmit infections to patients via the oral cavity. Obsolete models, powered by oil and without sophisticated air treatment systems, are ultimately likely to contaminate the very air that they supply to dental instruments with traces of oil and water, even with an extremely rigorous monitoring and maintenance schedule.
DentalAir.com compressors contain desiccant drying systems, which completely eliminate the moisture that is a by-product of the air compression process. Purchasing one of DentalAir. com's high-quality machines can improve your practice's regulatory compliance, lengthen the life of essential instruments, and most importantly of all protect your patients against any chance of infection. Reader response number 56 